\title{
Response of Controlled Cell Load Biofilms to Cold Atmospheric Plasma Jet: Evidence of Extracellular Matrix Contribution
}

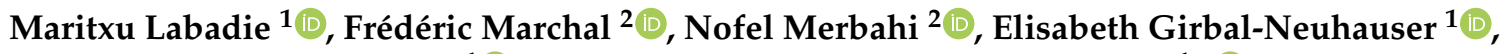 \\ Catherine Fontagné-Faucher ${ }^{1}$ (D) and Claire-Emmanuelle Marcato-Romain ${ }^{1, *(D)}$ \\ 1 UPS, IUT “A”, LBAE EA 4565 (Laboratoire de Biotechnologies Agroalimentaire et Environnementale), \\ Université de Toulouse, IUT Site d'AUCH, 24 rue d'Embaquès, F-32000 Auch, France; \\ labadie.maritxu@hotmail.fr (M.L.); elisabeth.neuhauser@iut-tlse3.fr (E.G.-N.); \\ cathy.faucher@iut-tlse3.fr (C.F.-F.) \\ 2 UPS, INPT, CNRS, LAPLACE UMR 5213 (Laboratoire Plasma et Conversion d'Energie), Université de \\ Toulouse, 118 Route de Narbonne, F-31062 Toulouse, France; frederic.marchal@laplace.univ-tlse.fr (F.M.); \\ nofel.merbahi@laplace.univ-tlse.fr (N.M.) \\ * Correspondence: claire-emmanuelle.romain@iut-tlse3.fr; Tel.: +33-562-61-63-05
}

\section{check for} updates

Citation: Labadie M.; Marchal F.; Merbahi N.; Girbal-Neuhauser E.; Fontagné-Faucher, C.;

Marcato-Romain, C.-E. Response of Controlled Cell Load Biofilms to Cold Atmospheric Plasma Jet: Evidence of Extracellular Matrix Contribution. Life 2021, 11, 694. https:/ / doi.org/ 10.3390/life11070694

Academic Editors: Gianluca De Masi and Emilio Martines

Received: 28 June 2021

Accepted: 13 July 2021

Published: 15 July 2021

Publisher's Note: MDPI stays neutral with regard to jurisdictional claims in published maps and institutional affiliations.

Copyright: (c) 2021 by the authors. Licensee MDPI, Basel, Switzerland. This article is an open access article distributed under the terms and conditions of the Creative Commons Attribution (CC BY) license (https:/ / creativecommons.org/licenses/by/ $4.0 /)$.
Abstract: Aim: Study of the biocidal effect of a cold atmospheric-pressure plasma in ambient air on single-species bacterial biofilms with controlled cell density, characterized by different extracellular matrices. Methods and results: Two bacterial strains were chosen to present different Gram properties and contrasted extracellular matrices: Pseudomonas aeruginosa ATCC 15442 (Gram-negative), and Leuconostoc citreum NRRL B-1299 (Gram-positive). P. aeruginosa biofilm exhibits a complex matrix, rich in proteins while L. citreum presents the specificity to produce glucan-type exopolysaccharides when grown in the presence of sucrose. Plasma was applied on both surface-spread cells and 24-h grown biofilms with controlled cell loads over 5, 10, or $20 \mathrm{~min}$. Surface-spread bacteria showed a time dependent response, with a maximal bacterial reduction of $2.5 \mathrm{log}$ after $20 \mathrm{~min}$ of treatment. On the other hand, in our experimental conditions, no bactericidal effect could be observed when treating biofilms of P. aeruginosa and glucan-rich L. citreum. Conclusions: For biofilms presenting equivalent cell loads, the response to plasma treatment seemed to depend on the properties of the extracellular matrix characterized by infrared spectroscopy, scanning electron microscopy, or dry weight. Significance and impact of study: Both cell load standardization and biofilm characterization are paramount factors to consider the biocide effect of plasma treatments. The extracellular matrix could affect the plasma efficacy by physical and/or chemical protective effects.

Keywords: P. aeruginosa; L. citreum; bacterial survival; extracellular polymeric substances; ATR-FTIR; non-thermal plasma; biofilm

\section{Introduction}

Biofilms are microbial communities attached to a surface and embedded in a selfproduced matrix of extracellular polymeric substances. Biofilms can colonize biotic or abiotic surfaces, hence leading to various detrimental effects in the medical, food, and industrial sectors [1]. The extracellular matrix (ECM) consists of a fully hydrated crosslinked complex mixture of proteins, polysaccharides, and extracellular DNA (eDNA). The biofilm matrix has diverse functions, such as maintaining the structural integrity of the biofilm and protecting cells from adverse environmental conditions [2]. Moreover, biofilm cells are in a different physiologic state compared to planktonic cells, and it is well known that bacteria growing within a biofilm structure have a higher resistance to desiccation and antimicrobials, compared to their planktonic counterparts. This enhanced tolerance has been attributed to a slower metabolism, protective proteins, and the presence of the matrix itself which can provide a physical barrier to prevent the penetration of antimicrobials $[1,3]$.

Cold atmospheric-pressure plasma (CAP), is considered as an innovative biofilm control strategy, and is currently developing as an environmentally-friendly method in 
order to reduce bacterial biofilms on surfaces [4]. Plasma, considered as the fourth state of matter, is defined as a highly reactive ionized gas with a net neutral charge. CAP can be experimentally generated by devices using an electromagnetic field and different noble gases, or even atmospheric air [5,6]. A huge variety of different plasma sources has been developed, the majority of which are based either on a dielectric barrier discharge (DBD), corona, or gliding arc discharges. Although the exact mechanism of CAP bactericidal action has still to be elucidated, it is nevertheless known that atmospheric air CAP is a source of multiple reactive species, including reactive oxygen and nitrogen species (RONS), excited molecules, and UV photons that contribute to the antimicrobial properties of plasmas [7-9]. Due to its decontaminating properties, CAP technology has been adopted for a wide range of applications going from food safety to biomedical domains, including oral health, wound healing, sterilization, and decontamination of inorganic and biomaterials $[10,11]$. The bactericidal effect of CAP on planktonic bacteria has been widely investigated $[8,12]$, while only fewer reports are available for biofilm inactivation. CAP efficiency against biofilm-forming bacteria was found less efficacious compared to planktonic bacteria and the duration of the treatment was usually increased [13-16]. However, numerous factors could impact the comparison of inactivation rates and/or efficacy of CAP treatments between studies and should also be considered in order to have a better understanding of the involved mechanisms: (i) Plasma-related factors, such as gas discharge composition, voltage and frequency of power supply, distance between biofilm surface and plasma electrode, and exposure time; and (ii) microbial-related factors, including bacterial concentration, biofilm thickness, and the nature and structure of extracellular polymers [12] . For instance, several reports underlined a reduced plasma efficacy when bacterial concentrations increased, as for planktonic E. coli [17-19] and Salmonella Typhimurium [20]. Therefore, standardizing biofilms in terms of cell density appears as a prerequisite in order to undertake a relevant analysis of a CAP treatment efficacy and to investigate the role of the extracellular matrix and/or the cellular compartment on biofilm resistance.

We here selected two bacterial strains: (i) Pseudomonas aeruginosa ATCC 15442, a Gramnegative bacterium that is recommended as a standard model for testing antimicrobial preservatives under national regulatory standards NF EN1040 (AFNOR 2006) and ASTM standards, and (ii) Leuconostoc citreum NRRL B-1299, a Gram-positive lactic acid bacterium which has the capacity to form thick biofilms due to the production of high-molecular weight dextrans in the presence of sucrose [21,22].

In this study, the main objectives were thus to: (i) Develop a method to standardize the production of mono-species bacterial biofilms formed by Pseudomonas aeruginosa and Leuconostoc citreum (with glucan-rich matrix or not); and (ii) investigate the influence of the extracellular matrix on the biofilm eradication potential of a plasma corona device operating in ambient air. Bacterial biofilms were standardized in terms of cell load and were characterized using dry weight, scanning electron microscopy, and ATR-FTIR spectroscopy. The bactericidal effect of the CAP treatment was then evaluated by the conventional plate count method and correlated to biofilm properties. Overall results are expected to shed light on the potential implication of extracellular matrix compounds within biofilms in response to CAP treatments.

\section{Materials and Methods}

\subsection{Bacterial Strains and Cultivation Method}

The two bacterial strains used in this study were Leuconostoc citreum NRRL B-1299 (ATCC 11449) and Pseudomonas aeruginosa ATCC 15442. This latter strain has a broad spectrum of resistance to various commercial germicides, is a non-mucoid strain, is neither invasive nor cytotoxic, and does not produce pyocyanin [23]. Stock cultures were maintained at $-80{ }^{\circ} \mathrm{C}$ in glycerol $(20 \% v / v)$ for both strains. L. citreum was routinely cultivated at $30^{\circ} \mathrm{C}$ in MRS (de Man Rogosa and Sharpe) medium, and the P. aeruginosa strain was cultivated at $37^{\circ} \mathrm{C}$ in the LB (Luria Bertani) medium. Control of the cell concentration was achieved by $O D_{600 \mathrm{~nm}}$ measurements, considering that an $O D_{600 \mathrm{~nm}}$ equal 
to 1.0 corresponded to $1.10^{8} \mathrm{CFU} / \mathrm{mL}$ for L. citreum and $3.10^{7} \mathrm{CFU} / \mathrm{mL}$ for P. aeruginosa, respectively.

\subsection{Biofilm Formation}

Biofilms were grown on sterile hydrophilic membranes (Pall GN-6 Metricel ${ }^{\circledR}$ sterile membranes, diameter $47 \mathrm{~mm}$, pore size $0.45 \mu \mathrm{m}$, with grids) as previously described by Marchal et al. [15] with slight modifications. Briefly, $20 \mathrm{~mL}$ of a calibrated suspension (obtained by dilution in fresh medium from an overnight suspension) were filtered through mixed cellulose ester membranes in order to homogeneously deposit the cells over the membrane surface. The membrane was then cut under sterile conditions in four equal squares of $1.5 \mathrm{~cm}^{2}$, and each individual coupon was immediately placed in the center of a Petri dish (55 mm diameter) containing either MRS solid media with or without sucrose $(40 \mathrm{~g} / \mathrm{L})$ for L. citreum, and LB solid media for P. aeruginosa. This process gave calibrated surface-spread bacteria (SSB) samples, which will be used directly for CAP treatments or for biofilm growth. For biofilm growth, plates were incubated during $24 \mathrm{~h}$ at $30{ }^{\circ} \mathrm{C}$ for L. citreum or $37^{\circ} \mathrm{C}$ for P. aeruginosa. The L. citreum biofilms grown on sucrose-containing medium will be called hereafter "glucan-rich biofilms". The total mass of biofilms and dry weight measurements were undertaken on 24-h biofilms grown on whole 47-mm membranes, with a moisture analyzer (Sartorius MA30) and the wet and dry mass of biofilms were corrected with the mass of the membrane.

\subsection{Plasma Source and Exposure}

The used CAP system was a direct current (DC) homemade corona system as previously described in several studies $[15,24,25]$. The CAP was composed of an anodic tungsten needle (20 - $\mu \mathrm{m}$ radius) inside a cylindrical brass cathode (20-mm inner diameter) linked to the ground. The plasma jet was supplied by a high-voltage generator through a resistor of $25 \mathrm{M} \Omega$ to avoid arcing. The voltage was adjusted at $14.7 \mathrm{kV}$. In this configuration, the plasma jet was generated directly in the ambient air at atmospheric pressure and launched by itself without any system of gas inlet feed. This corona discharge has a natural repetitive discharge current with a frequency of about $20 \mathrm{kHz}$. The electric power injected was about $100 \mathrm{~mW}$. The visible plasma effluent was approximately $15-20 \mathrm{~mm}$ long and $1-2 \mathrm{~mm}$ in diameter from the end of the cylindrical cathode.

Optical emission spectroscopy was used to estimate the radiative active species of the plasma effluent column generated by the corona discharge and launched on the L. citreum 24 h-biofilm. A spectrophotometer (Acton Spectra SP 2750, in the Czerny Turner configuration) with $0.75 \mathrm{~m}$ of focal length covering a spectral range lying between $200 \mathrm{~nm}$ and $900 \mathrm{~nm}$ was used in this study. The detecting device set at the exit of this spectrophotometer was a CCD camera (PIXIS 100, $1340 \times 100$ imaging array of $20 \mu \mathrm{m} \times 20 \mu \mathrm{m}$ pixels). The plasma spectra were collected through an optical fibre (UV-silicon LG-455-020-3) placed at the spectrometer entrance slit (being $50 \mu \mathrm{m}$ wide) and connected, on the plasma side, to an optical system (composed by 2 magnification lens) aimed to target a small plasma volume $\left(1 \mathrm{~mm}^{3}\right)$. Spectra collections were performed using a 2400 grooves $/ \mathrm{mm}$ grating in the UV range and a 1800 grooves $/ \mathrm{mm}$ grating in the visible range. An optical long-pass filter was used for the visible range in order to prevent second order effects caused by the grating second order diffracted beam.

Preliminary experiments were performed to evaluate the potential bacterial growth inhibition area by the plasma jet. Hence, $100 \mu \mathrm{L}$ of an overnight $L$. citreum suspension were spread over MRS agar plates, left to dry for $15 \mathrm{~min}$, and exposed for $20 \mathrm{~min}$ to the plasma treatment. The area of bacterial growth inhibition was measured after incubation for $24 \mathrm{~h}$ at $30^{\circ} \mathrm{C}$. Secondly, to examine the thermal or dehydration effect of the plasma, the temperature was measured along the axis of the plasma jet using a thermocouple, and the mass of agar plates before and after $30 \mathrm{~min}$ of exposure was evaluated in triplicate, respectively. 
For treatment of SSB and biofilm samples, plasma was applied directly in the center of each coupon, and the agar plate was not moved during treatment. The distance between the target sample and the end of the cylindrical cathode of the plasma jet was set at $20 \mathrm{~mm}$. Three coupons provided from the same membrane were treated for 5, 10, and $20 \mathrm{~min}$, respectively, and the fourth coupon was left untreated (as a control sample) to estimate the initial bacterial concentration on the membrane.

\subsection{ATR-FTIR Spectroscopy}

For FTIR analysis, biofilm samples (before and after plasma exposure) were dehydrated by using a moisture analyzer (Sartorius MA30). The coupons were heated at $45^{\circ} \mathrm{C}$ until reaching constant weight. The spectra of bacterial cells without matrix were obtained by analyzing dehydrated pellets of overnight microbial cultures. The extracellular glucan polymer fraction from L. citreum NRRL B-1299 was produced by enzymatic reaction from sucrose and purified as previously described by Bounaix et al. [21]. The FTIR spectra were recorded between 4000 and $800 \mathrm{~cm}^{-1}$ on a Spectrum 65 spectrometer equipped with the Spectrum software (Perkin Elmer). Each spectrum was an average of 32 scans with a resolution of $4 \mathrm{~cm}^{-1}$. For all spectra, baselines were corrected. Spectra were normalized on the $1280 \mathrm{~cm}^{-1}$ peak, which corresponds to a distinctive peak from the membrane, and with low abundance for bacterial cells and biofilm spectra. Band assignments were made according to the literature [26,27]. Moreover, in order to compare the different spectra, a ratio was calculated based on the responses obtained at $1540 \mathrm{~cm}^{-1}$ (amide II) and $1070 \mathrm{~cm}^{-1}$ (polysaccharides), which will be called hereafter AmII/PS. The amide II band was preferred to the amide I band to represent the protein fraction of the samples due to the absence of response of the membrane at this wave number. Finally, the overall similarity $(p<0.05)$ between spectra from glucan-rich and dextrans was directly provided by the data processing software.

\subsection{Scanning Electron Microscopy}

Scanning electron microscopy (SEM) analysis was applied on bacterial biofilms, which were produced as described previously. Coupons were removed from agar plates and were desiccated under vacuum for $15 \mathrm{~min}$ to $1 \mathrm{~h}$, depending on the samples. No fixation step or staining was performed, as previously proposed by Lackmann et al. [28]. Samples were then metallized with platinum to allow image acquisition. Analysis was performed with a MEB Quanta 250 FEG FEI at the microscopy platform, Centre de Microscopie Électronique Appliquée à la Biologie (CMEAB) in Toulouse.

\subsection{Bacterial Viability}

Membrane coupons of untreated control and plasma-exposed samples were placed into $1 \mathrm{~mL}$ of saline sterile solution $(\mathrm{NaCl} 9 \mathrm{~g} / \mathrm{L})$ and vigorously mixed by vortexing $1 \mathrm{~min}$, which disrupted biofilms and released bacterial cells. Serial ten-fold dilutions were then achieved on the obtained bacterial suspensions, and CFU counts were determined in duplicate on appropriate culture media. The efficacy of this initial recovery step was checked by counting the bacterial cells remaining on the membrane coupon: Coupons were once again placed into $1 \mathrm{~mL}$ of sterile physiological solution and treated as described above. These experiments showed that more than $95 \%$ of cells could be recovered from the coupon by applying the one-step procedure.

Cultivable cell reduction values were calculated by subtracting the $\log \mathrm{CFU} \mathrm{cm} \mathrm{cm}^{-2}$ of treated coupons from the $\log \mathrm{CFU} \mathrm{cm} \mathrm{cm}^{-2}$ of their own control coupon i.e., provided from the same membrane sample.

\subsection{Statistical Analysis}

All experiments were conducted in triplicate, with independent initial bacterial culture, and results were expressed as mean \pm SEM. A one-way ANOVA was conducted and the 
Newman-Keuls multiple comparison test was used to determine the level of significance against the untreated control value $(p<0.05)$.

\section{Results}

\subsection{Standardization and Characterization of the Bacterial Model Biofilms}

The methodology applied to produce the biofilms on the membrane led to significantly comparable cell loads with concentrations reaching $8 \log \mathrm{CFU} \mathrm{cm}{ }^{-2}$ for both L. citreum and P. aeruginosa biofilms (Table 1 ). Although similar cell densities were obtained for both $L$. citreum biofilms, whether produced with sucrose or not, dry weight, on the other hand, was 4-fold higher for biofilms cultivated on sucrose supplemented medium, demonstrating the production of glucan polymers (Table 1). All the biofilms were well-hydrated with moisture contents of $82 \%$ and $92 \%$ for L. citreum (glucan-rich or not, respectively) and $90 \%$ for $P$. aeruginosa. SEM also allows one to visualize the homogeneous distribution of $L$. citreum and P. aeruginosa cells on the membrane coupons (Figure 1). Images showed that all biofilms obtained after $24 \mathrm{~h}$ of culture were composed of densely arranged cells, covering the whole surface of the membrane. However, biofilms were physically different: A layer of smooth distinct cells for L. citreum biofilm grown on MRS media, cells embedded in a thick slimy matrix due to the overproduction of glucans for L. citreum biofilm grown on sucrose supplemented media, and a rough surface for P. aeruginosa biofilm.

Table 1. Biofilm characteristics regarding cell density and biomass. Bacterial population was recovered from untreated 24-h biofilms formed on mixed cellulose esters membrane coupon and expressed as $\log \mathrm{CFU} \mathrm{cm}{ }^{-2}$. $n$ : replicate number.

\begin{tabular}{cccc}
\hline & P. aeruginosa & L. citreum & \\
& & without Sucrose & with Sucrose \\
\hline Cells density $(\log$ CFU cm & & $8.8 \pm 0.26(n=6)$ \\
Wet mass $(\mathrm{mg})$ & $8.07 \pm 0.46(n=6)$ & $8.36 \pm 0.45(n=8)$ & $466 \pm 23(n=3)$ \\
Dry mass $(\mathrm{mg})$ & $314 \pm 21(n=3)$ & $255 \pm 21(n=3)$ & $82 \pm 9.9(n=3)$ \\
\hline
\end{tabular}

ATR-FTIR spectroscopy confirmed that the membrane support is well covered by the biofilms (Figure 2). Indeed, distinctive peaks of the mixed cellulose ester membrane that could be observed at $1280 \mathrm{~cm}^{-1}$ and $840 \mathrm{~cm}^{-1}$ were no longer visible after a $24-\mathrm{h}$ biofilm development (Figure 2). The value of the amide II/polysaccharide (AmII/PS) ratio measured at $1540 \mathrm{~cm}^{-1}$ and $1070 \mathrm{~cm}^{-1}$ peaks (Table 2) revealed that proteins are relatively more present in P. aeruginosa cells (average ratio 1.28) than in L. citreum cells (average ratio 0.88 ). The corresponding $24-\mathrm{h}$ biofilms presented a slight increase in protein content compared to the cells alone. P. aeruginosa biofilm maintained higher protein content (average ratio 1.39) whereas L. citreum biofilm showed a more equilibrated pattern between proteins and polysaccharides (average ratio 1.14). Obviously, a large proportion of polysaccharides, shown as intense peaks ranging from 1200 to $1000 \mathrm{~cm}^{-1}$ was detected on L. citreum biofilms grown on a sucrose-containing medium, with an AmII/PS ratio of only 0.16 . FTIR measurements on purified glucan fractions produced by planktonic L. citreum cells grown on sucrose showed a similar spectrum (correlation coefficient of 95\%), confirming the abundance of glucans in the ECM. 

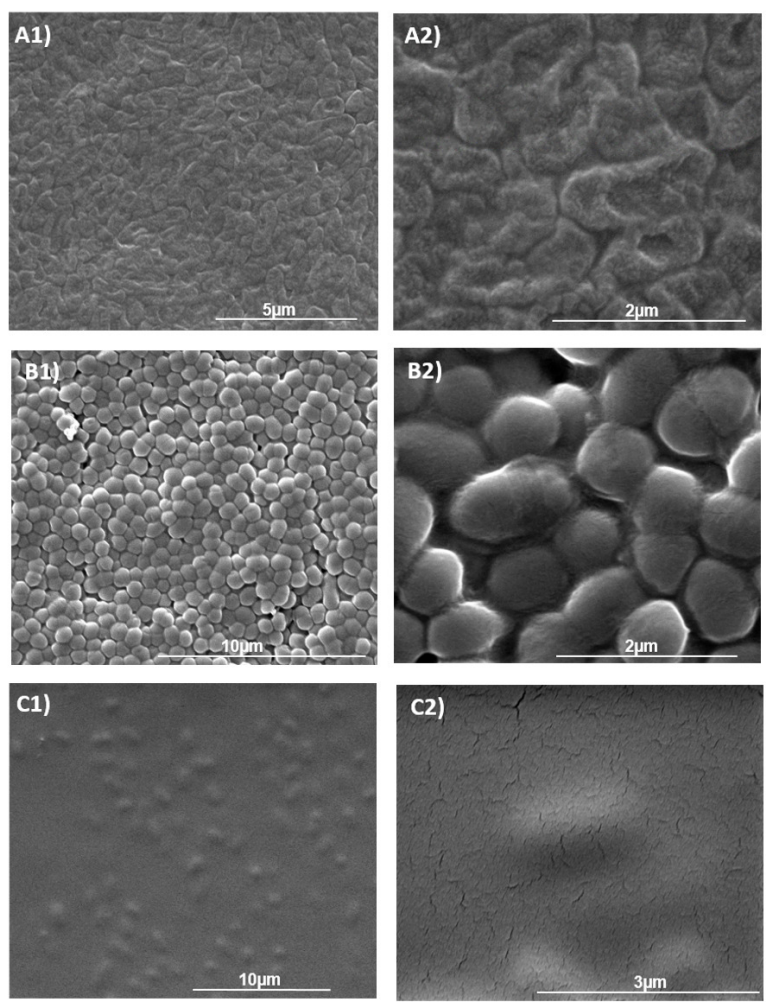

Figure 1. SEM observations of the 24-h biofilms formed on mixed cellulose ester membrane coupon. (A) P. aeruginosa biofilm on LB medium; (B) L. citreum biofilm on MRS medium, (C) L. citreum biofilm on sucrose $\left(40 \mathrm{~g} \mathrm{~L}^{-1}\right)$ containing MRS. (A1-C1) at low magnification and (A2-C2) at high magnification.

Table 2. Intensity of the Amide II/Polysaccharide ratio for planktonic cells and biofilms. Ratio was calculated from ATR-FTIR spectra for wave numbers $1540 \mathrm{~cm}^{-1}$ (Amide II) and $1070 \mathrm{~cm}^{-1}$ (polysaccharides) after normalization of the spectra on a distinctive peak of the membrane $\left(1280 \mathrm{~cm}^{-1}\right)$.

\begin{tabular}{lccc}
\hline & P. aeruginosa & \multicolumn{2}{c}{ L. citreum } \\
& & without Sucrose & with Sucrose \\
\hline Cells & 1.28 & \multicolumn{2}{c}{0.88} \\
24 h biofilm-untreated & $1.39 \pm 0.03$ & $1.14 \pm 0.04$ & $0.16 \pm 0.01$ \\
24 h biofilm-treated 20 min & $0.95 \pm 0.20$ & $0.63 \pm 0.20$ & $0.13 \pm 0.04$ \\
\hline
\end{tabular}

\subsection{Characteristics of Corona Plasma Jet}

Emission spectra were recorded during biofilm treatments (Figure 3). Overall, results revealed the presence of excited molecular species like nitrogen $\mathrm{N}_{2}$, molecular ion of nitrogen $\mathrm{N}_{2}^{+}$, and free radicals of $\mathrm{OH}$ and $\mathrm{O}$ in the vicinity of the bacterial biofilm during the plasma treatment. In particular, emissions of atomic oxygen could be observed at 777 and $844 \mathrm{~nm}$. No emissions were detected at a wavelength below $250 \mathrm{~nm}$, indicating that no UV-C photons had been produced in our plasma effluent. Ozone concentration, produced by the reaction of atomic oxygen with the molecular oxygen of the surrounding environment, was estimated 60-80 ppm nearby the sample (data not shown). Measured temperature at the surface of the biofilm did not exceed $27^{\circ} \mathrm{C}$, thereby precluding the heat effect from the plasma. Inactivation of bacteria can be here also excluded from a dehydration effect. Indeed, the loss of water content was estimated at less than $3 \%$ when mass of agar plates was compared before and after $30 \mathrm{~min}$ of treatment. This can be 
attributed to the ionic wind jet produced by the plasma regarding DC corona discharge configuration.

A)
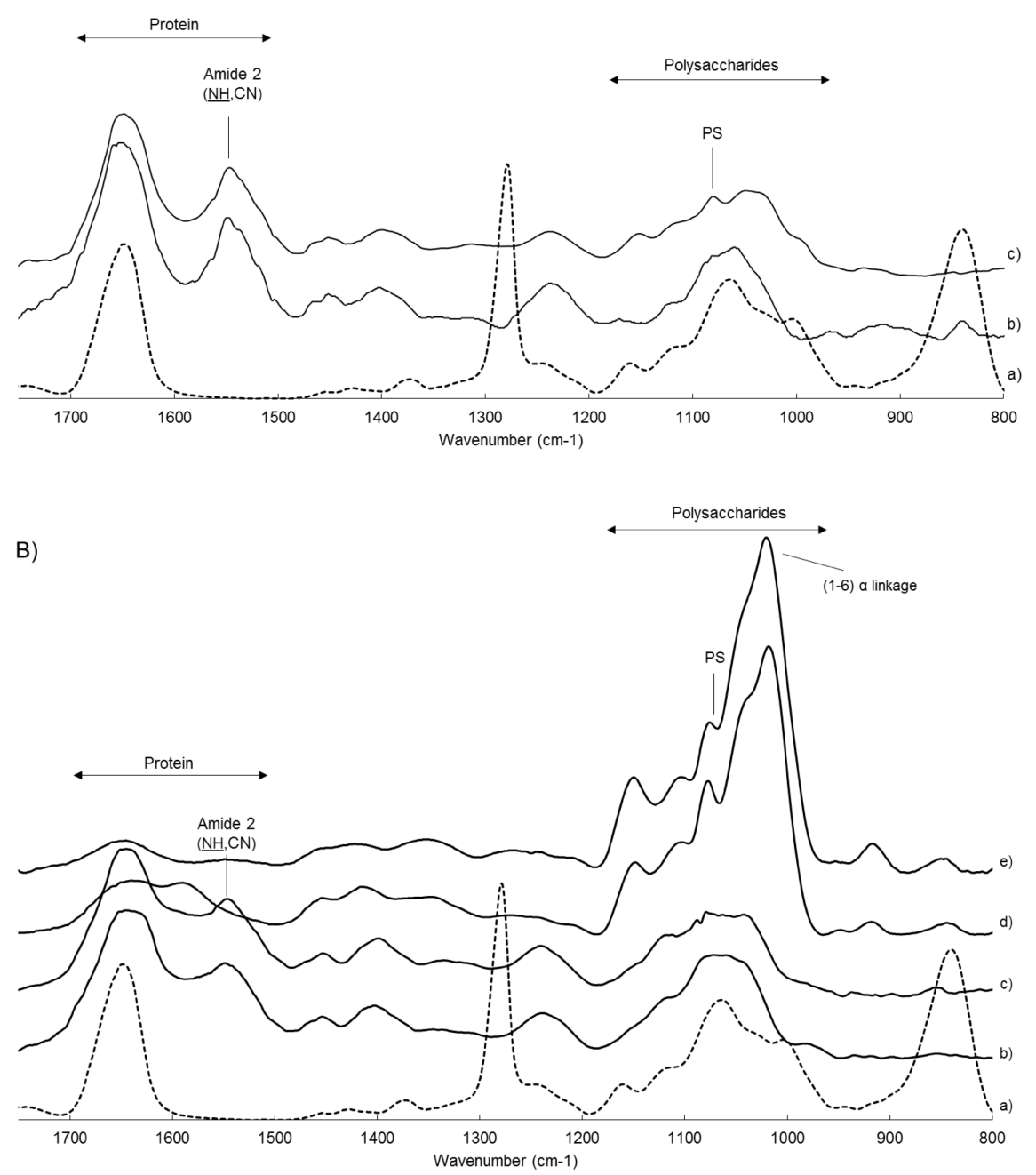

Figure 2. ATR-FTIR spectra of 24-h biofilms compared to planktonic cells and membrane coupon. (A) P. aeruginosa spectra: (a) Uninoculated membrane, (b) cells of P. aeruginosa, and (c) 24-h biofilm. (B) L. citreum spectra: (a) Uninoculated membrane, (b) cells, (c) 24-h biofilm, (d) glucan-rich 24-h biofilm, and (e) purified glucan polymer. Each spectrum undergoes a baseline correction and for better visibility, each absorbance was expressed in total absorbance percentage and spectra have been vertically shifted.

\subsection{Cold Plasma Jet Treatment of Surface-Spread Cells}

Preliminary experiments were conducted with L. citreum to determine the surface targeted by the plasma effluent in terms of the bacterial growth inhibition area. Even if the diameter of air plasma jet is about $2 \mathrm{~mm}$, the plasma inhibited the growth of bacterial cells over a circular surface of higher diameter $(28 \pm 1 \mathrm{~mm}, n=3)$, probably due to the spreading of the active species generated by the plasma jet into the agar medium. As this inhibition area was really larger than the square coupon surface $\left(150 \mathrm{~mm}^{2}\right)$, it could be suggested that all bacteria deposited or grown on the coupons can be affected by the treatment. For both strains, the eradication efficacy of surface-spread bacteria (SSB) increased with the time of treatment, with a maximal reduction reached after 20 min (Figure 4). For P. aeruginosa, a significant $1.8 \log$ bacterial reduction could be observed from a 5-min plasma exposure, to a maximum reduction of $2.3 \log$ after $20 \mathrm{~min}$. A similar response was observed for $L$. citreum: Approximately $1.4 \log$ after $5 \mathrm{~min}$ of treatment to a maximum of $2.4 \log$ reduction 
after $20 \mathrm{~min}$. Extended treatment time was investigated up to $40 \mathrm{~min}$ on both strains and results did not reveal an increase in efficacy (data not shown).

A)

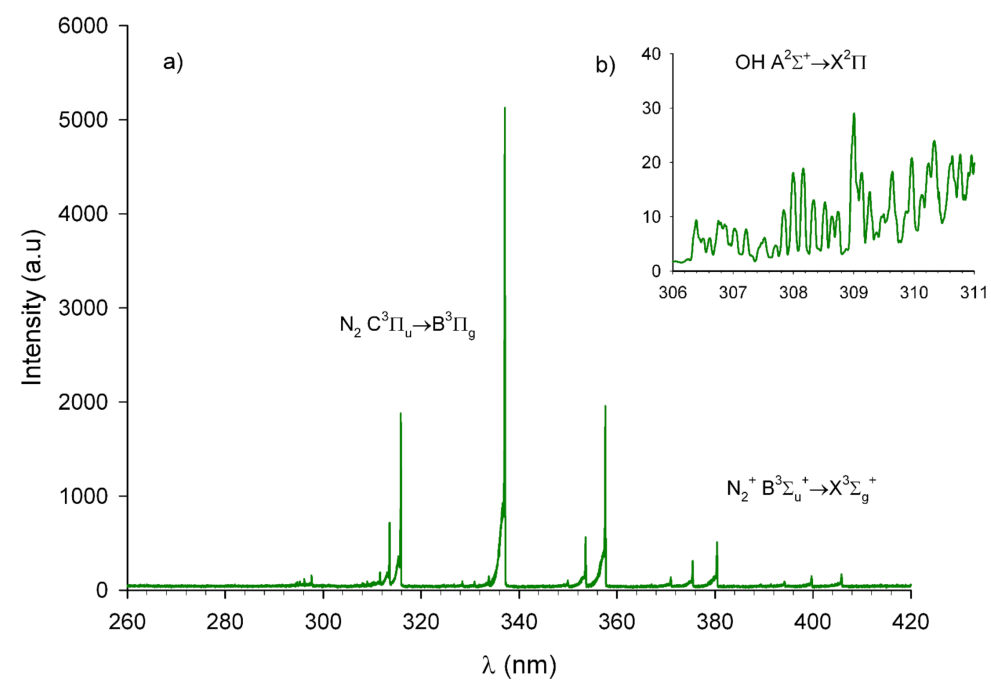

B)

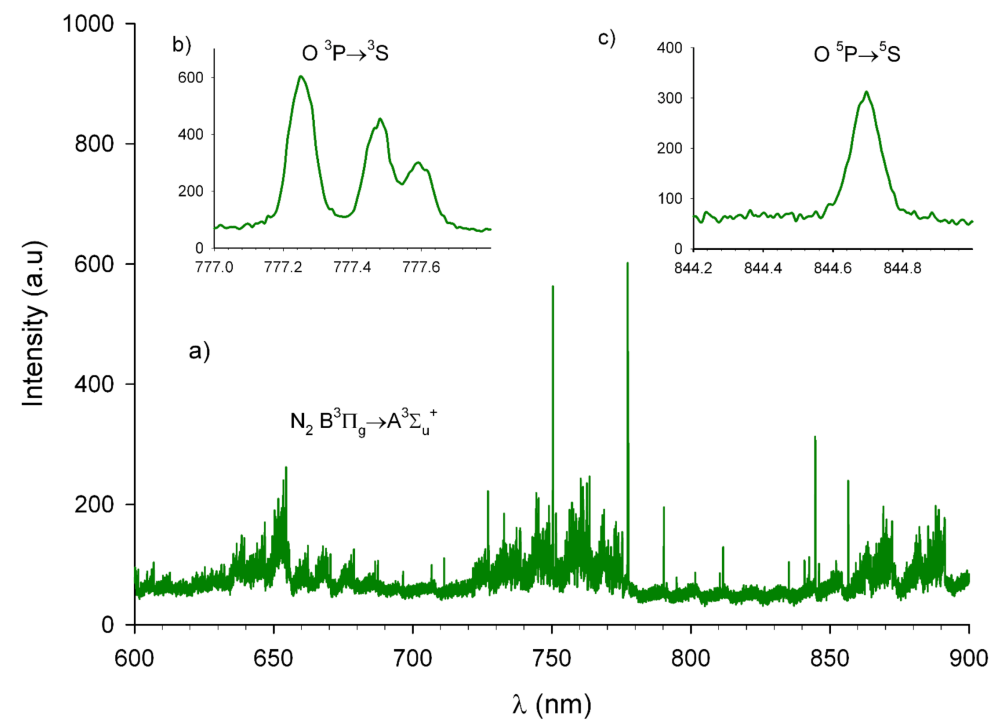

Figure 3. Emission spectra of corona plasma around the needle of the plasma device during L. citreum biofilm treatment. (A) Emission spectra in the UV range. No emission was detected for a wavelength lower than $250 \mathrm{~nm}$. (a) Observation of the second positive nitrogen system from $290 \mathrm{~nm}$ to $440 \mathrm{~nm}$ and the first negative nitrogen system around $392 \mathrm{~nm}$, (b) OH(A-X) emission from $306 \mathrm{~nm}$ to $312 \mathrm{~nm}$ recorded with an exposure time 300 -fold higher. (B) Emission spectra in the visible range. (a) Observation of the first positive nitrogen system from $650 \mathrm{~nm}$ to $750 \mathrm{~nm}$, (b) emission of atomic oxygen at $777 \mathrm{~nm}$, and (c) at $844 \mathrm{~nm}$. 


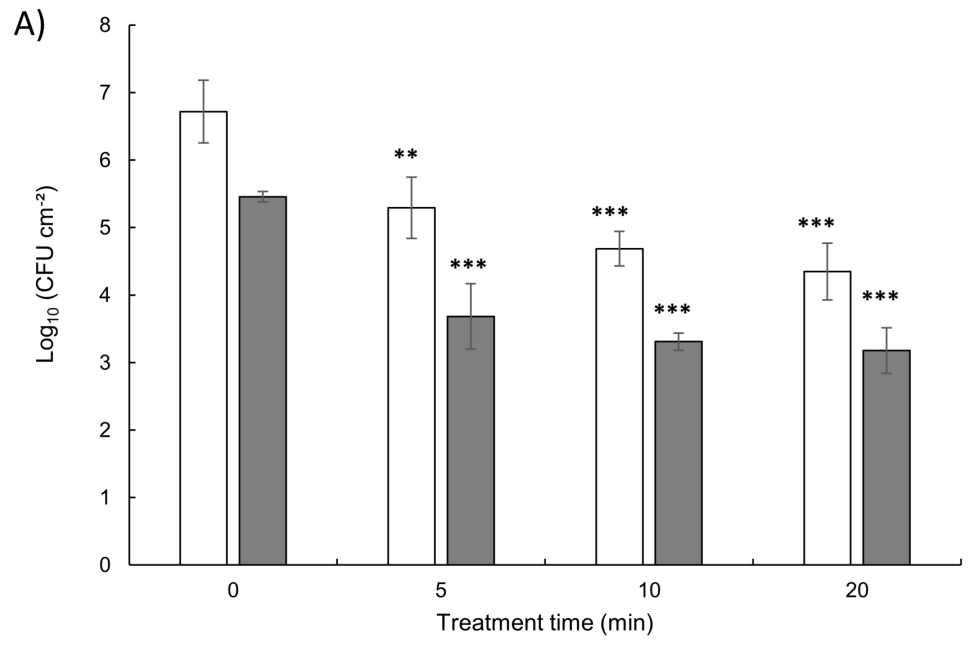

B)

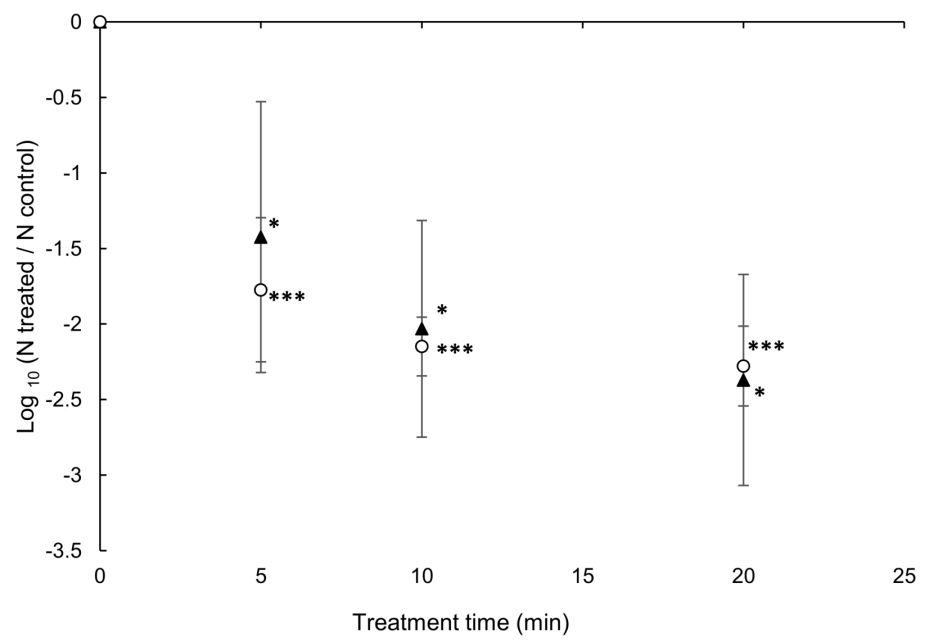

Figure 4. Survival curves for surface-spread bacteria after plasma treatment. (A) Bacterial population in CFU cm ${ }^{-2}$ before and after plasma exposure from 5, 10, and $20 \mathrm{~min}$ for P. aeruginosa (grey bar) and L. citreum (open bar); (B) logarithmic reduction of the bacterial population for P. aeruginosa $(\mathbf{\Lambda})$ and $L$. citreum ( $\left(\right.$ ). Data represent means $\pm s d$ from three independent experiments $\left({ }^{*}, p<0.05,{ }^{* *}, p<0.01\right.$ and ${ }^{* * *}, p<0.001$ against the negative control as measured by the Newman-Keuls test).

\subsection{Viability of Biofilm Cells after Plasma Exposure}

When 24-h P. aeruginosa biofilms were treated in the same conditions as above, no bactericidal effect could be observed even after 20 min of treatment (Figure 5). Similar results were obtained when L. citreum biofilms were produced in the presence of sucrose, i.e., with a high production of extracellular glucan polymers. Conversely, CAP exposure was significantly effective to reduce $24-h$ L. citreum biofilms with a similar cell density than the previously described biofilms, by a $1.5 \mathrm{log}$ reduction after $20 \mathrm{~min}$ of treatment. SEM images of $L$. citreum and $P$. aeruginosa biofilms after plasma exposure did not reveal noticeable differences in cell size, shape, and surface structure of treated cells versus untreated controls (data not shown). This is relevant with the observations of Soler-Arango et al. [29] who imaged $P$. aeruginosa $\mathrm{PAO} 1$ biofilms treated with plasma for 0,3 , and $30 \mathrm{~min}$. These authors did not observe significant damage either to the matrix or to the cell morphology for a 3-min treatment, even if a disorganization of the biofilm with distorted and broken cells and matrix disintegration appeared for the highest dose. The comparison between normalized ATR-FTIR spectra of L. citreum and P. aeruginosa biofilms before and after a 20-min plasma jet treatment (Figure S1) revealed that only L. citreum biofilm (without sucrose addition) 
showed a significantly different profile. However, we could observe that the AmII/PS ratio decreased by approximately 30 to $40 \%$ for $P$. aeruginosa and L. citreum biofilms, respectively (Table 2), indicating in both cases a relative loss of protein residues. These observations are relevant with the results of Soler-Arango et al. [29] who provided evidence that the biofilm exposure to plasma produced significant modifications in the biomass content and denaturation or aggregation of proteins at the highest exposure time.

A)

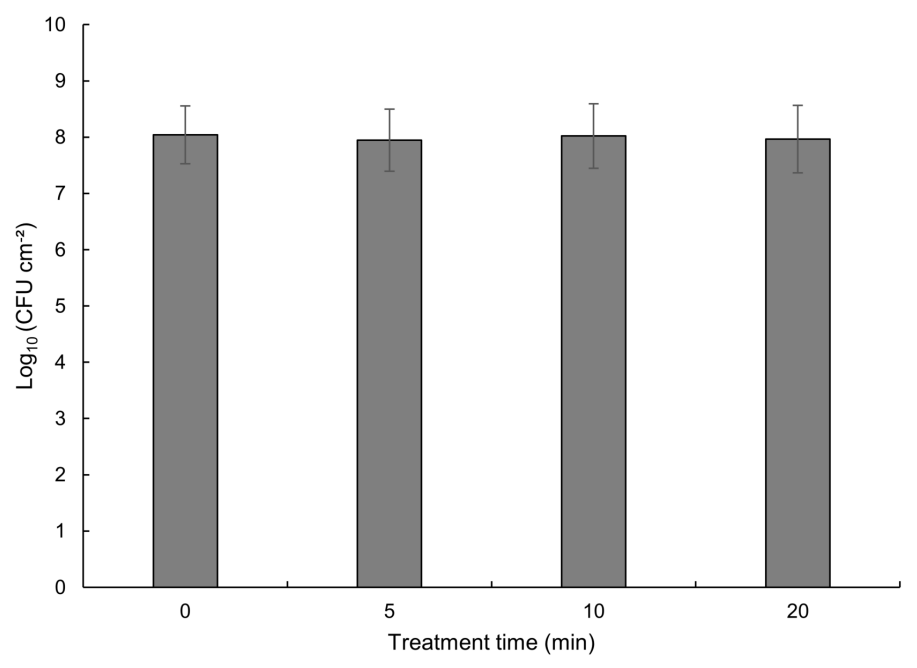

B)

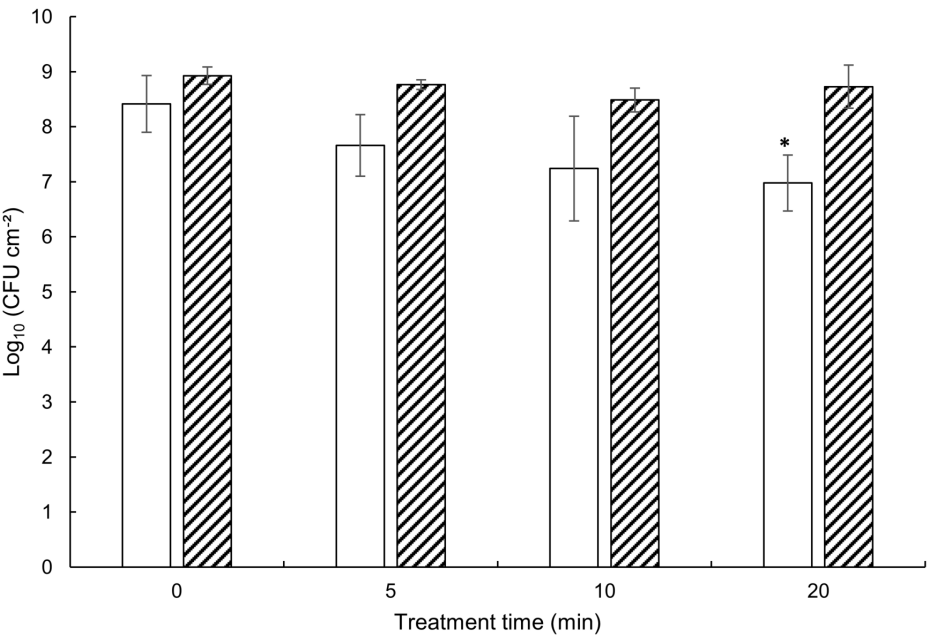

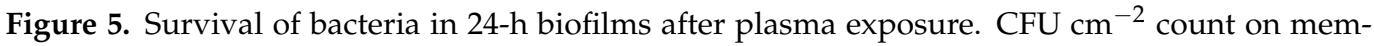
brane coupon before and after plasma exposure for 5, 10, and $20 \mathrm{~min}$ for (A) P. aeruginosa and (B) L. citreum grown without (open bar) or with (hatched bar) sucrose. Data represent means $\pm s d$ from three independent experiments $(*: p<0.05$ against the negative control as measured by the Newman-Keuls test).

\section{Discussion}

In this study, we aimed at highlighting the potential implication of the extracellular matrix in the response of 24-h biofilms to CAP treatment, while also controlling cell density to about a similar $8 \log \mathrm{CFU} / \mathrm{cm}^{2}$ for all samples. P. aeruginosa and L. citreum strains were selected to target biofilm-forming bacteria with different cell wall structures, respectively Gram-negative and Gram-positive, and also because these two bacterial species present contrasted extracellular matrices when growing into biofilms, as described in detail below. To date, there is still no consensus on the plasma resistant property of Gram-positive versus 
Gram-negative bacteria [8], and the ECM is still rarely taken into account as a parameter potentially affecting CAP efficacy.

As judged by MEB observations and ATR-FTIR results, the methodology applied in this study clearly provided uniform and homogeneous biofilms covering the whole coupon surface, with similar cell loads but different extracellular matrices. Deposition of cells obtained by calibrated suspensions through filtration on the membrane coupon, rather than by simple surface deposits, certainly contributed to the formation of a homogeneous biofilm, as previously reported by Bayliss et al. [30]. Interest in the initial microbial load of biofilm is, to date, rarely considered, especially that bacterial density can vary from 3 to $9 \log \mathrm{cm}^{-2}$ depending on the study, and sometimes vary even within the same study, with values more often below $6 \log [13,31-33]$. In addition, the contribution of cell density could be masked when the expression of plasma efficacy is only reported by a single logarithmic reduction.

The (untreated) biofilm characterization by a quantitative approach, using the dry weight of 24-h biofilms, clearly showed the importance of the ECM: The dry weight values of the L. citreum glucan-rich biofilms were 2-fold higher than the P. aeruginosa biofilms, and 4 -fold higher than the L. citreum biofilms grown on the MRS medium alone.

In addition, ATR-FTIR spectroscopy was selected for its rapid and broad in situ analysis of the biofilms by providing qualitative information on the nature of the components of the matrix, and also relative quantitative information of some type of compounds [26,34]. Despite inherent complexity of ATR-FTIR bacterial spectra, this technique has been successfully employed to monitor the early stages of biofilm formation [26,34] and also once recently employed to investigate biofilm eradication by plasma technology using a submerged dielectric barrier discharge plasma [27]. In our study, the calculated AmII/PS ratio revealed that the biofilm produced by $P$. aeruginosa ATCC 15442 was rich in proteins. This is consistent with previous reports that showed the presence of abundant proteins, especially amyloids fibrils, along with extracellular DNA and polysaccharides within the biofilm matrix of this strain in a microplate assay [35,36], and as usually described for others non-mucoid P. aeruginosa strains $[37,38]$. On the contrary, L. citreum biofilms have been poorly studied so far $[39,40]$, however this present study showed that $L$. citreum NRRL B-1299 produced biofilms with a lower relative protein content. Furthermore, the extracellular glucane-saccharases produced by this strain allow to control the production of abundant glucan exopolymers of the dextran type [22,41]. This is achieved in a very easy and simple way, since adding sucrose into the culture medium provides the only substrate required by these extracellular enzymes. It was also shown here that purified glucan polymer fraction from planktonic culture and glucan-rich L. citreum 24-h biofilm both presented similar spectra with a notable intense peak at $1020 \mathrm{~cm}^{-1}$, characteristic of $\alpha-(1,6)$ glucosidic linkages which are abundant in dextran polymers [42].

The main concern of our work was to study the implication of the ECM in the biofilm response to CAP treatment. Treatment of surface-spread cells of P. aeruginosa and L. citreum (without any incubation period) revealed a significant antibacterial time-dependent effect of the CAP treatment. Indeed the cultivability of the bacteria was reduced significantly from $5 \mathrm{~min}$ of treatment to a maximal effect reaching less than 1\% survival cells after $20 \mathrm{~min}$ of exposure. These results confirmed a previous report on evaluating the effect of a similar plasma device with another LAB strain [15]. Unlike some other reports [31,32], we did not observe a higher sensitivity of the Gram-negative P. aeruginosa strain to plasma exposure, compared to the Gram-positive L. citreum. Actually, it is often argued that Gram-negative bacteria are more CAP sensitive due to the inherent thin layer of the peptidoglycan which composes its cell wall [31,32]. However, other factors such as the overall thickness and the other compounds of the cell envelope can also be taken into account [43].

When treating 24-h biofilms with an initial load of approximately $8 \log$ bacteria $\mathrm{CFU} \mathrm{cm}{ }^{-2}$, a significant time-dependent cultivability reduction was only observed for $L$. citreum biofilms but without any bactericidal efficacy on $P$. aeruginosa and glucan-rich $L$. citreum biofilms. Accurate direct comparison with the results obtained from the surface- 
spread condition is rather difficult since the initial microbial load was higher (by a factor 40 to 200) due to the used protocol, which was developed to obtain constant cell density biofilms after $24 \mathrm{~h}$. Therefore, plasma inefficacy within biofilms in respect to SSB could be here attributed to both a higher microbial load and the presence of matrix compounds. However, as initial cell loads for the three biofilms were not significantly different, and also because of their specific biomasses, results obtained in this study thus highlighted the contribution of the ECM in response to CAP treatments. In addition, the data of plasmainduced bacterial reduction for L. citreum biofilms grown with or without the addition of sucrose were statistically different, indicating that production of glucans clearly impaired plasma efficacy. Data showed that the cultivability reduction could be explained quite well $\left(r^{2}=0.88\right)$ by taking into account simultaneously the treatment time as well as initial matrix properties (biofilm AmII/PS ratio and total dry weight).

It is generally accepted that the antimicrobial properties of cold plasma are predominantly attributed to the production of reactive oxygen and nitrogen species (RNOS) and in some cases to UV radiations [7-9]. These were not present in the plasma jet under the experimental conditions of this study, thus excluding their action. On the other hand, optical emission spectra showed that the plasma jet produced reactive oxygen species (ROS) such as $\mathrm{O}$ and $\mathrm{OH}$ and reactive nitrogen species (RNS) such as $\mathrm{N}_{2}^{*}$ and $\mathrm{N}_{2}^{+}$. These reactive species generated during biofilm contact were similar to what has been previously detected when applying this specific plasma device simply in the air [15]. Only OH emissions (in the spectral region from 306 to $312 \mathrm{~nm}$ ) were different, due to the ambient humidity caused by the presence of agar media under the coupon. These species generated in the plasma, might also react with the liquid surrounding the bacteria leading to form antibacterial by-products such as peroxides and superoxides $[4,6]$.

The exact mechanisms underlying bactericidal inactivation by cold plasma are still unclear and it is assumed that multiple actions due to the diversity of active agents are playing a role in the permeabilization of cell walls and/or membranes, and in protein damage and enzyme inactivation [7-9]. RNOS are known to exhibit strong oxidative properties, and are able to degrade biomacromolecules, including proteins, lipids, nucleic acids, as well as polysaccharides [44], present both as cellular and matrix components of biofilms. The role of excited $\mathrm{N}_{2}^{*}$ species is expected to be less significant in the bacteriainactivation process compared to ROS species [45]. In agreement with these assumptions, reduced cell viability after CAP treatment revealed to be time-dependant for surface-spread bacteria as well as for biofilms exposing low extracellular compound contents. Moreover, despite the absence of bactericidal effect on biofilms presenting thick matrices, ATR-FTIR measurements revealed a 30\% reduction in the amount of protein residues (as evaluated by amide II band) in the P. aeruginosa biofilm after $20 \mathrm{~min}$ of plasma exposure. This is in agreement with Khan et al. [27] who showed that the protein peak region was reduced by 10 to $20 \%$ (also based on AmII/PS ratio) after exposing three different biofilms to a DBD plasma reactor which eradicated $90 \%$ of the bacterial population. In addition, reports on in vitro plasma exposures of purified proteins showed diverse structural alterations $[6,8]$.

One frequent argument to explain why plasma efficacy upon biofilms is reduced, is the presence of the extracellular matrix, who acts as a physical barrier to antimicrobials, thereby preventing the penetration of plasma active species [4]. However, ROS species are expected to easily penetrate the biofilms and impact the bacteria deep inside them. For instance, it was reported that ROS generated by plasma were able to penetrate right through to the bottom layer of a $25.5 \mu \mathrm{m}$ thick Enterococcus faecalis biofilm when using a plasma jet, operating in open air [46]. Components of the matrix can also act as a chemical barrier protecting the cells by possible scavenging of biocidal compounds, as previously mentioned [33,47]. Accordingly, Yan et al. [48] recently reported that extracellular glucan produced by Leuconostoc mesenteroides could improve the survival of cells during chronic oxidative stress. Other polysaccharides, such as alginate, a heteropolysaccharide excreted in mucoid $P$. aeruginosa matrix, are also likely to be involved in scavenging hydroxyl radicals $(\mathrm{OH})$ and $\mathrm{H}_{2} \mathrm{O}_{2}$ [49]. As evidence, Gilmore et al. [50] reported that the addition 
of $1.25 \%$ alginate to planktonic cells of P. aeruginosa PA01 increased the survival from 52\% to $91 \%$ after a DBD plasma jet exposure. These results on planktonic P. aeruginosa PAO1 cells were recently confirmed: A protective effect was observed, at lower exposure times to an atmospheric pressure nonthermal plasma (APNTP), after the addition of exogenous alginate or DNA, with an additive protective effect with alginate and DNA together [51]. These authors also reported that the endogenous production of alginate by a $P$. aeruginosa mutant strain overexpressing alginate to form biofilms that had a protective effect against the antimicrobial action of the plasma treatment [51].

Overall results obtained in this study indicate that the ECM in thick biofilms, such as P. aeruginosa and glucan-rich L. citreum biofilms has most probably a role in the resistance to plasma treatment. This is in agreement with previous studies that have shown that (i) clinical isolates of Burkholderia cepacia producing the highest amount of biomass were more tolerant to the biocide effect of CAP [52], and (ii) that Acinetobacter baumannii biofilm biomass mediates tolerance to cold plasma [53].

In conclusion, this study allowed to produce similar biofilms in terms of cell densities but are different in terms of matrix composition, and thus to evaluate the contribution of the ECM in the response to CAP treatments. Notably, these in vitro 24 h-old mono-species biofilms did not represent complex natural biofilms, but were used as standardized tools that are able to produce highly reproducible biofilms for accurate comparative laboratory scale studies. In these conditions, the experiments showed that the characteristics of extracellular matrix in which cells are embedded drastically affect CAP sensitivity. The ECM of biofilms is complex and varies depending on the type of bacteria (species and strain) within the biofilm and on the growth conditions. The ECM should be thus considered, along with the microbial load, when studying the effectiveness of CAP technology. Further studies are now required to better understand the interactions of plasma reactive species within the organic matrix of biofilms.

Supplementary Materials: The following are available online at https://www.mdpi.com/article/10 .3390/life11070694/s1, Figure S1: Comparison of ATR-FTIR spectra from untreated and cold plasma treated 24 h-biofilm samples A) P. aeruginosa biofilm, B) L. citreum biofilm, and C) glucan-rich L. citreum biofilm. In each figure, uninoculated membrane $(\cdots)$, untreated sample $(-)$, and treated for $20 \mathrm{~min}$ (-). Ranging from 1800 to $800 \mathrm{~cm}^{-1}$, ATR-FTIR spectra were normalized on the peak of the membrane at $1280 \mathrm{~cm}^{-1}$.

Author Contributions: Methodology, F.M., C.F.-F. and C.-E.M.-R.; validation, F.M., N.M., C.F.-F. and C.-E.M.-R. ; investigation, M.L., F.M., N.M., C.F.-F. and C.-E.M.-R.; resources, M.L., F.M., N.M., C.F.-F. and C.-E.M.-R.; writing—original draft preparation, M.L., F.M., N.M., E.G.-N., C.F.-F. and C.-E.M.-R.; writing-review and editing, F.M., N.M., C.F.-F. and C.-E.M.-R.; visualization, M.L., F.M., N.M., E.G.-N., C.F.-F. and C.-E.M.-R.; supervision, F.M., C.F.-F. and C.-E.M.-R.; project administration, F.M., C.F.-F. and C.-E.M.-R.; funding acquisition, N.M., E.G.-N., C.F.-F. and C.-E.M.-R. All authors have read and agreed to the published version of the manuscript.

Institutional Review Board Statement: Not applicable.

Informed Consent Statement: Not applicable.

Data Availability Statement: Not applicable.

Funding: This research was funded by by grants from the Toulouse University Paul Sabatier and Occitanie Regional Council (grants no. 14055695, no. 12050475). Maritxu Labadie was supported by a fellowship from the Occitanie Regional Council (ALDOCT-000268/2017 001895), IUT 'A' Paul Sabatier ad Auch ad Gers Local Concils.

Acknowledgments: The authors also thank the "Centre de Microscopie Electronique Appliquée à la Biologie (CMEAB)" in Toulouse for their SEM facilities, David Collado for his help in statistical analyses, and Monique Ras-de Moncuit (Blue Science) for proof-reading the manuscript.

Conflicts of Interest: The authors declare no conflict of interest. 


\section{References}

1. Bridier, A.; Briandet, R.; Thomas, V.; Dubois-Brissonnet, F. Resistance of bacterial biofilms to disinfectants: A review. Biofouling 2011, 27, 1017-1032. [CrossRef]

2. Flemming, H.C.; Wingender, J. The biofilm matrix. Nat. Rev. Microbiol. 2010, 8, 623-633. [CrossRef]

3. Branda, S.S.; Vik, Å.; Friedman, L.; Kolter, R. Biofilms: the matrix revisited. Trends Microbiol. 2005, 13, 20-26. [CrossRef]

4. Gilmore, B.F.; Flynn, P.B.; O’Brien, S.; Hickok, N.; Freeman, T.; Bourke, P. Cold Plasmas for Biofilm Control: Opportunities and Challenges. Trends Biotechnol. 2018, 36, 627-638. [CrossRef]

5. Moreau, M.; Orange, M.; Feuilloley, M.G.J. Non-thermal plasma technologies: New tools for bio-decontamination. Biotechnol. Adv. 2008, 26, 610-617. [CrossRef]

6. Lackmann, J.W.; Bandow, J.E. Inactivation of microbes and macromolecules by atmospheric-pressure plasma jets. Appl. Microbiol. Biotechnol. 2014, 98, 6205-6213. [CrossRef]

7. Mai-Prochnow, A.; Murphy, A.B.; McLean, K.M.; Kong, M.G.; Ostrikov, K.K. Atmospheric pressure plasmas: Infection control and bacterial responses. Int. J. Antimicrob. Agents 2014, 43, 508-517. [CrossRef]

8. Liao, X.; Liu, D.; Xiang, Q.; Ahn, J.; Chen, S.; Ye, X.; Ding, T. Inactivation mechanisms of non-thermal plasma on microbes: A review. Food Control 2017, 75, 83-91. [CrossRef]

9. Flynn, P.B.; Gilmore, B.F. Understanding plasma biofilm interactions for controlling infection and virulence. J. Phys. Appl. Phys. 2018, 51, 263001. [CrossRef]

10. Yousfi, M.; Merbahi, N.; Pathak, A.; Eichwald, O. Low-temperature plasmas at atmospheric pressure: Toward new pharmaceutical treatments in medicine. Fundam. Clin. Pharmacol. 2014, 28, 123-135. [CrossRef]

11. Pankaj, S.K.; Wan, Z.; Keener, K.M. Effects of Cold Plasma on Food Quality: A Review. Foods 2018, 7, 4. [CrossRef] [PubMed]

12. Bourke, P.; Ziuzina, D.; Han, L.; Cullen, P.J.; Gilmore, B.F. Microbiological interactions with cold plasma. J. Appl. Microbiol. 2017, 123, 308-324. [CrossRef]

13. Kamgang, J.; Briandet, R.; Herry, J.; Brisset, J.; Naïtali, M. Destruction of planktonic, adherent and biofilm cells of Staphylococcus epidermidis using a gliding discharge in humid air. J. Appl. Microbiol. 2007, 103, 621-628. [CrossRef] [PubMed]

14. Salamitou, S.; Kirkpatrick, M.J.; Ly, H.M.; Leblon, G.; Odic, E.; DuBow, M.S. Augmented Survival of Bacteria Within Biofilms to Exposure to an Atmospheric Pressure Non-Thermal Plasma Source. Biotechnology 2009, 8, 228-234. [CrossRef]

15. Marchal, F.; Robert, H.; Merbahi, N.; Fontagné-Faucher, C.; Yousfi, M.; Romain, C.E.; Eichwald, O.; Rondel, C.; Gabriel, B. Inactivation of Gram-positive biofilms by low-temperature plasma jet at atmospheric pressure. J. Phys. Appl. Phys. 2012, 45, 345202. [CrossRef]

16. Puligundla, P.; Mok, C. Potential applications of nonthermal plasmas against biofilm-associated micro-organisms in vitro. J. Appl. Microbiol. 2017, 122, 1134-1148. [CrossRef]

17. Yu, H.; Perni, S.; Shi, J.J.; Wang, D.Z.; Kong, M.G.; Shama, G. Effects of cell surface loading and phase of growth in cold atmospheric gas plasma inactivation of Escherichia coli K12. J. Appl. Microbiol. 2006, 101, 1323-1330. [CrossRef]

18. Joshi, S.G.; Cooper, M.; Yost, A.; Paff, M.; Ercan, U.K.; Fridman, G.; Friedman, G.; Fridman, A.; Brooks, A.D. Nonthermal Dielectric-Barrier Discharge Plasma-Induced Inactivation Involves Oxidative DNA Damage and Membrane Lipid Peroxidation in Escherichia coli. Antimicrob. Agents Chemother. 2011, 55, 1053-1062. [CrossRef]

19. Judée, F.; Wattieaux, G.; Merbahi, N.; Mansour, M.; Castanié-Cornet, M.P. The antibacterial activity of a microwave argon plasma jet at atmospheric pressure relies mainly on UV-C radiations. J. Phys. Appl. Phys. 2014, 47, 405201. [CrossRef]

20. Fernàndez, A.; Shearer, N.; Wilson, D.; Thompson, A. Effect of microbial loading on the efficiency of cold atmospheric gas plasma inactivation of Salmonella enterica serovar Typhimurium. Int. J. Food Microbiol. 2012, 152, 175-180. [CrossRef] [PubMed]

21. Bounaix, M.S.; Gabriel, V.; Morel, S.; Robert, H.; Rabier, P.; Remaud-Siméon, M.; Gabriel, B.; Fontagné-Faucher, C.M.S.B.; Gabriel, V.; Robert, H.; et al. Biodiversity of Exopolysaccharides Produced from Sucrose by Sourdough Lactic Acid Bacteria. J. Agric. Food Chem. 2009, 57, 10889-10897. [CrossRef]

22. Passerini, D.; Vuillemin, M.; Ufarté, L.; Morel, S.; Loux, V.; Fontagné-Faucher, C.; Monsan, P.; Remaud-Siméon, M.; Moulis, C. Inventory of the GH70 enzymes encoded by Leuconostoc citreum NRRL B-1299-identification of three novel $\alpha$-transglucosylases. FEBS J. 2015, 282, 2115-2130. [CrossRef]

23. Wang, Y.; Li, C.; Gao, C.; Ma, C.; Xu, P. Genome Sequence of the Nonpathogenic Pseudomonas aeruginosa Strain ATCC 15442. Microbiol. Resour. Announc. 2014, 2. [CrossRef] [PubMed]

24. Merbahi, N.; Yousfi, M.; Eichwald, O. Device for Emitting a Plasma Jet from the Atmospheric Pressure Air at Ambient Temperature and Pressure, and Use of Said Device. Patent WO 2011/00170 A1, 1 June 2011.

25. Marchal, F.; Robert, H.; Sejer, D.; Merbahi, N.; Randrianjatovo, I.; Fontagné-Faucher, C.; Di Martino, P.; Yousfi, M.; Neuhauser, E. Atmospheric cold plasmas for biofilm inactivation: does biofilm extracellular matrix limit the bactericidal process? J. Eng. Technol. Res. 2013, 1, 123-135.

26. Quilès, F.; Humbert, F.; Delille, A. Analysis of changes in attenuated total reflection FTIR fingerprints of Pseudomonas fluorescens from planktonic state to nascent biofilm state. Spectrochim. Acta Part Mol. Biomol. Spectrosc. 2010, 75, 610-616. [CrossRef]

27. Khan, M.S.I.; Lee, E.J.; Kim, Y.J. A submerged dielectric barrier discharge plasma inactivation mechanism of biofilms produced by Escherichia coli O157:H7, Cronobacter sakazakii, and Staphylococcus aureus. Sci. Rep. 2016, 6, 37072. [CrossRef] 
28. Lackmann, J.W.; Schneider, S.; Edengeiser, E.; Jarzina, F.; Brinckmann, S.; Steinborn, E.; Havenith, M.; Benedikt, J.; Bandow, J.E. Photons and particles emitted from cold atmospheric-pressure plasma inactivate bacteria and biomolecules independently and synergistically. J. R. Soc. Interface 2013, 10, 20130591. [CrossRef]

29. Soler-Arango, J.; Figoli, C.; Muraca, G.; Bosch, A.; Brelles-Mariño, G. The Pseudomonas aeruginosa biofilm matrix and cells are drastically impacted by gas discharge plasma treatment: A comprehensive model explaining plasma-mediated biofilm eradication. PLoS ONE 2019, 14, e0216817. [CrossRef]

30. Bayliss, D.L.; Walsh, J.L.; Iza, F.; Shama, G.; Holah, J.; Kong, M.G. Complex Responses of Microorganisms as a Community to a Flowing Atmospheric Plasma. Plasma Process. Polym. 2012, 9, 597-611. [CrossRef]

31. Flynn, P.B.; Higginbotham, S.; Alshraiedeh, N.H.; Gorman, S.P.; Graham, W.G.; Gilmore, B.F. Bactericidal efficacy of atmospheric pressure non-thermal plasma (APNTP) against the ESKAPE pathogens. Int. J. Antimicrob. Agents 2015, 46, 101-107. [CrossRef]

32. Mai-Prochnow, A.; Clauson, M.; Hong, J.; Murphy, A.B. Gram positive and Gram negative bacteria differ in their sensitivity to cold plasma. Sci. Rep. 2016, 6, 38610. [CrossRef] [PubMed]

33. Helgadóttir, S.; Pandit, S.; Mokkapati, V.R.S.S.; Westerlund, F.; Apell, P.; Mijakovic, I. Vitamin C Pretreatment Enhances the Antibacterial Effect of Cold Atmospheric Plasma. Front. Cell. Infect. Microbiol. 2017, 7, 43. [CrossRef]

34. Humbert, F.; Quilès, F. Science against Microbial Pathogens: Communicating Current Research and Technological Advances; formatex microbiology ed.; Antonio Mendez-Vilas: Badajoz, Spain 2011; chapter In-situ study of early stages of biofilm formation under different environmental stresses by ATR-FTIR spectroscopy, pp. 889-895.

35. Randrianjatovo, I.; Girbal-Neuhauser, E.; Marcato-Romain, C.E. Epicocconone, a sensitive and specific fluorescent dye for in situ quantification of extracellular proteins within bacterial biofilms. Appl. Microbiol. Biotechnol. 2015, 99, 4835-4844. [CrossRef] [PubMed]

36. Randrianjatovo-Gbalou, I.; Girbal-Neuhauser, E.; Marcato-Romain, C.E. Quantification of biofilm exopolysaccharides using an in situ assay with periodic acid-Schiff reagent. Anal. Biochem. 2016, 500, 12-14. [CrossRef]

37. Mann, E.E.; Wozniak, D.J. Pseudomonas biofilm matrix composition and niche biology. FEMS Microbiol. Rev. 2012, 36, 893-916. [CrossRef] [PubMed]

38. Wei, Q.; Ma, L.Z. Biofilm Matrix and Its Regulation in Pseudomonas aeruginosa. Int. J. Mol. Sci. 2013, 14, 20983-21005. [CrossRef]

39. Badel, S.; Laroche, C.; Gardarin, C.; Bernardi, T.; Michaud, P. New Method Showing the Influence of Matrix Components in Leuconostoc mesenteroides Biofilm Formation. Appl. Biochem. Biotechnol. 2008, 151, 364-370. [CrossRef]

40. Leathers, T.D.; Bischoff, K.M. Biofilm formation by strains of Leuconostoc citreum and L. mesenteroides. Biotechnol. Lett. 2011, 33, 517-523. [CrossRef] [PubMed]

41. Bounaix, M.S.; Robert, H.; Gabriel, V.; Morel, S.; Remaud-Siméon, M.; Gabriel, B.; Fontagné-Faucher, C. Characterization of dextran-producing Weissella strains isolated from sourdoughs and evidence of constitutive dextransucrase expression. FEMS Microbiol. Lett. 2010, 311, 18-26. [CrossRef]

42. Purama, R.K.; Goswami, P.; Khan, A.T.; Goyal, A. Structural analysis and properties of dextran produced by Leuconostoc mesenteroides NRRL B-640. Carbohydr. Polym. 2009, 76, 30-35. [CrossRef]

43. Han, L.; Patil, S.; Boehm, D.; Milosavljević, V.; Cullen, P.J.; Bourke, P. Mechanisms of Inactivation by High-Voltage Atmospheric Cold Plasma Differ for Escherichia coli and Staphylococcus aureus. Appl. Environ. Microbiol. 2016, 82, 450-458. [CrossRef]

44. Duan, J.; Kasper, D.L. Oxidative depolymerization of polysaccharides by reactive oxygen/nitrogen species. Glycobiology 2010, 21, 401-409. [CrossRef]

45. Laroussi, M. Low-Temperature Plasmas for Medicine? IEEE Trans. Plasma Sci. 2009, 37, 714-725. [CrossRef]

46. Pei, X.; Lu, X.; Liu, J.; Liu, D.; Yang, Y.; Ostrikov, K.; Chu, P.K.; Pan, Y. Inactivation of a $25.5 \mu$ m Enterococcus faecalisbiofilm by a room-temperature, battery-operated, handheld air plasma jet. J. Phys. Appl. Phys. 2012, 45, 165205. [CrossRef]

47. Alkawareek, M.Y.; Algwari, Q.T.; Gorman, S.P.; Graham, W.G.; O'Connell, D.; Gilmore, B.F. Application of atmospheric pressure nonthermal plasma for the in vitro eradication of bacterial biofilms. Pathog. Dis. 2012, 65, 381-384. [CrossRef]

48. Yan, M.; Han, J.; Xu, X.; Liu, L.; Gao, C.; Zheng, H.; Chen, Y.; Tao, Y.; Zhou, H.; Li, Y.; et al. Gsy, a novel glucansucrase from Leuconostoc mesenteroides, mediates the formation of cell aggregates in response to oxidative stress. Sci. Rep. 2016, 6, 38122. [CrossRef] [PubMed]

49. Gambino, M.; Cappitelli, F. Mini-review: Biofilm responses to oxidative stress. Biofouling 2016, 32, 167-178. [CrossRef] [PubMed]

50. Gilmore, B.F. The matrix revisited: understanding the role of extracellular matrix components in biofilm tolerance to atmospheric pressure non-thermal plasma exposure. In Proceedings of the 22nd International Symposium on Plasma Chemistry, Antwerp, Belgium, 5-10 July 2015.

51. Alshraiedeh, N.H.; Kelly, S.A.; Thompson, T.P.; Flynn, P.B.; Tunney, M.M.; Gilmore, B.F. Extracellular polymeric substancemediated tolerance of Pseudomonas aeruginosa biofilms to atmospheric pressure nonthermal plasma treatment. Plasma Process. Polym. 2020, 17, 2000108. [CrossRef]

52. Alshraiedeh, N.H.; Higginbotham, S.; Flynn, P.B.; Alkawareek, M.Y.; Tunney, M.M.; Gorman, S.P.; Graham, W.G.; Gilmore, B.F. Eradication and phenotypic tolerance of Burkholderia cenocepacia biofilms exposed to atmospheric pressure non-thermal plasma. Int. J. Antimicrob. Agents 2016, 47, 446-450. [CrossRef] [PubMed]

53. Flynn, P.; Graham, W.; Gilmore, B. Acinetobacter baumannii biofilm biomass mediates tolerance to cold plasma. Lett. Appl. Microbiol. 2019, 68, 344-349. [CrossRef] 